\title{
Towards a socially consistent science and technology policy
}

\author{
Narendar Pani
}

The development of science and technology $(S \& T)$ in India is widely believed to have not quite lived up to the high expectations in the Scientific Policy Resolution of 1958. To paraphrase a major scientist, it has had tall peaks towering over some much more modest achievements. This article traces some of these shortcomings to the divergence between the direction which the $S \& T$ policies have advocated and the socio-economic road the country has taken. Based on an analysis of this divergence, the article argues for a new Science and Technology Policy based on a much broader conception of technology.

Keywords: Innovations, policy resolution, science, technology.

ECONOMISTS have recognized, particularly since Solow's ${ }^{1}$ seminal paper in 1957 , that technological progress can be at least as significant a contributor to economic growth as capital accumulation. In the decades soon after Indian independence, Jawaharlal Nehru did provide a leading role for science and technology (S\&T) in India's development strategy. The drive to making the Indian economy globally competitive, particularly after 1991, has however been driven primarily by a search for capital. The reform process has focused on enabling foreign capital to enter previously debarred areas, the mechanisms for the entry of portfolio investment have been transformed to make them more globally attractive ${ }^{2}$, capital markets have been streamlined to enable large Indian companies to raise capital more efficiently ${ }^{3}$, and efforts have been made to generate and use state resources to provide capital for large infrastructure projects ${ }^{4}$. In this entire process the technological challenge has been largely underemphasized. This article argues that the receding of technology from its pride of place in India's economic strategy is due to a mismatch between technology policy and economic transformation. It makes its case by first tracing the main rationale for India's technology policies. Then it goes on to consider the economic context in which these policies had to operate and finally argues for a broader conception of technology, noting the implications this would have for technology policy.

\section{Rationale of technology policies}

The long-term strategy underlying Indian S\&T policies is still perhaps best captured by the Scientific Policy Reso-

Narendar Pani is in the National Institute of Advanced Studies, Indian Institute of Science Campus, Bengaluru 560 012, India.

e-mail: narendar.pani@gmail.com lution of 1958. It argued that 'The key to national prosperity, apart from the spirit of the people, lies, in the modern age, in the effective combination of the three factors, technology, raw material and capital, of which the first is perhaps the most important, since the creation and adoption of new scientific techniques can, in fact, make up for a deficiency in natural resources, and reduce the demands on capital ${ }^{5}$. The strategy to achieve technological progress was to focus primarily on three sets of interventions. First, the policy aimed to ensure 'an adequate supply, within the country, of research scientists of the highest quality' ${ }^{6}$. This was to be achieved by ensuring creative talent found full scope in scientific activity and by providing academic freedom for the discovery of new knowledge. Second, the policy aimed to encourage, 'with all possible speed" ${ }^{6}$, the training of scientific and technical personnel. And third, 'to secure for the people of the country all the benefits that can accrue from the acquisition and application of scientific knowledge ${ }^{6}$.

Underlying this strategy was a distinct perspective on the relationship between science and society. The development of science was believed to have its own independent trajectory. All that was needed was to provide an adequate supply of high-quality research scientists who would discover what science had to offer. What science had to offer, in turn, would necessarily be good for society. This understanding of the relationship between science and society had its implications for the more actionable dimensions of this policy. First, it encouraged an approach where scientists were to be isolated from society. It could be argued that this approach was already deeply entrenched in Indian attitudes to science. There was a widely held belief that science was best left to those who could afford to spend their time doing little else. When laying the foundation stone for the main building of the Indian Institute of Science, Bengaluru in 1911, the then 


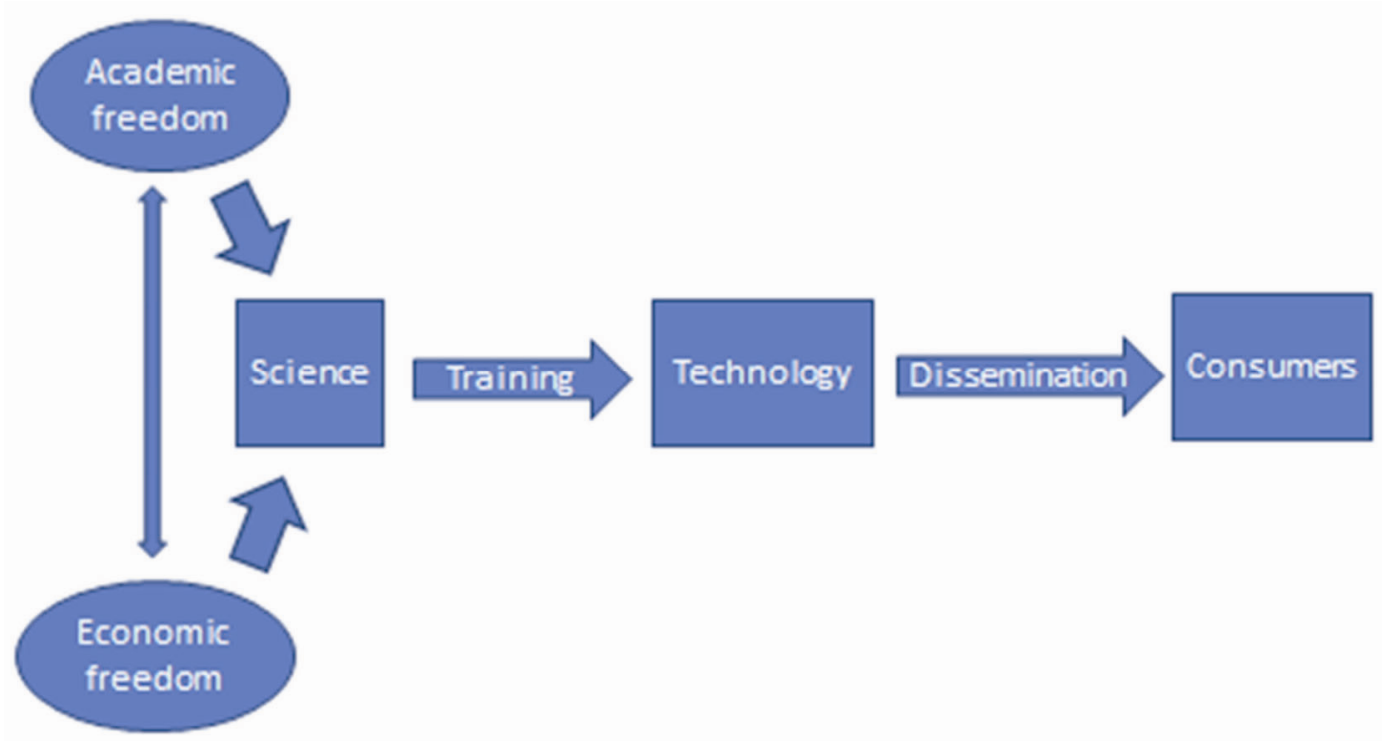

Figure 1. The logical flow of the Scientific Policy Resolution.

Maharaja of Mysore acknowledged the dominant view that scientific research should be restricted to those with independent means ${ }^{7}$, even as he argued for scholarships to be provided for students of brilliant abilities but limited means. This approach of providing scientists state supported insulation from societal pressures was extended into the 1958 Policy. Second, the training of technical personnel was to be carried out 'on a scale adequate to fulfil the country's needs in science and education, agriculture and industry, and defence ${ }^{6}$. Implicit in this clause was the understanding that the Government would intervene at the stage of training to ensure technological development followed the priorities it set. And third, it was assumed that what the scientists discovered would be what the people wanted. In practice, this often turned into a belief that if the people did not eagerly seek what the scientists had to offer, it was due to a lack of effective communication. Figure 1 presents the underlying logic of the Scientific Policy Resolution.

It did not take long for the gaps in this Policy to become evident. The connections between different stages of the Policy were not seamless. The supply of research scientists increased to a level that could not be absorbed by the pace of technological growth. As the scientists sought greener pastures abroad, it led to a situation where the Indian Government was meeting the training costs of scientists operating in the developed world, the so-called brain drain ${ }^{8}$. The scientific interests of those that remained were not always consistent with the priorities of a still poor country. The needs of the poor, and those of the backward regions, often required incremental scientific developments rather than the major new scientific findings which scientists liked to pursue. As a result, essential technological requirements for development still had to be imported.
The then Governments saw this as essentially a problem of a gap between science and technology. This thinking resulted in the Technology Policy Statement of 1983, whose objective was the 'attainment of technological self-reliance, a swift and tangible improvement in the conditions of the weakest sections of the population and the speedy development of backward regions"9.

Even as the 1983 Policy was being pursued, the world of technology was itself going through a dramatic transformation. The information and communication technology revolution was transforming the global scientific environment. The Science and Technology Policy 2003 saw this challenge through the lens of the earlier policies of 1958 and 1983. It made it clear that 'They embody a vision and strategy that are applicable today, and would continue to inspire us in our endeavors ${ }^{10}$. Thus, even as the Policy brought a wide range of new issues on board beginning with coming up with a common S\&T policythe underlying strategy for scientific development remained the same as in the 1958 Policy. It reaffirmed that the development of independent academic institutions, preferably insulated from the normal pressures of Indian society, would throw up the required scientific expertise. All that was needed was to strengthen its infrastructure to match the technological changes that had taken place elsewhere in the world. It reaffirmed the Government's dominant role in listing priorities. And it continued to see the problem of the acceptance of the results of Indian S\&T as essentially one of dissemination, rather than finding out what the society may actually want. In the words of the 2003 Resolution, the challenge would 'call for the generation and screening of all relevant technologies, their widespread dissemination through networking and support for the vast unorganized sector of our economy ${ }^{11}$. 
The approach of adding changes that had already occurred to the existing strategy continued into the Science, Technology and Innovation Policy 2013. The case for such a policy was built around the need to take on board the fact that innovation 'has assumed centre stage in the developmental goals of nations ${ }^{\prime 2}$. As innovations usually occur in practice, this could have been expected to affect the 1958 approach, where scientists were expected to work in complete freedom from society. But this potential problem was avoided by restricting the concept of innovation to imply only S\&T-based solutions 'that are successfully deployed in the economy or in society" ${ }^{13}$.

\section{Economic context of technology policy}

The economic context in India has seen more fundamental changes in strategy than the somewhat limited changes in technology policy. We can mark at least three different phases in the Indian economy since independence. In the first Nehruvian phase, the economic and industrial strategy was dominated by the Second Plan model that advocated state supported heavy industry - including the S\&T that went with it - in the expectation that this would lead to a substantial base on which future growth could take off. The many public sector units and the IITs are examples of this strategy. Agriculture found no major role in this strategy.

Barely six years after the Scientific Policy Resolution, the country was on the brink of a famine. It was also clear that the Second Plan model was not providing results as rapidly as a democratizing country was demanding. The official response to this crisis led to the second phase of economic strategy based on poverty alleviation measures. Underlying this response were two technological initiatives. First, the Government took the initiative in setting targets for agricultural scientists. The result was the green revolution where the lab-to-land process achieved substantial increases in crop productivity, at least in some areas, for noticeable periods of time ${ }^{14}$. The depth of the crisis also forced a greater emphasis on self-reliance in industrial policy, a direction which was to be later adopted in the Technology Policy of 1983. With the prospects of making globally recognized technological changes receding, the focus shifted to seeking individual technological jewels that could be placed in the crown of Indian modernity.

In the years soon after man's landing on the moon, it was natural for a space programme to be seen as the ideal project that would keep India's image of technological progress alive, even as a major portion of its resources was diverted to patronage politics. In 1972, the space programme in India was initiated through a project in the Department of Atomic Energy. And in the succeeding decades it was to grow to become one of India's leading technological achievements. But this strategy of supporting a few successful programmes did not always have a large enough technological spillover to lift the overall level of technological development in the country. As one of India's leading scientists was to note, 'The best in the country is often about as good as anywhere else in the world, but the worst is poor; tall peaks tower over a low average, 15 .

The low average in technological abilities contributed to making the Indian economy less competitive, with its consequences for India's exports. The sustained pressure on the foreign exchange reserve finally resulted in the crisis of 1991, which required the opening up of the Indian economy. In this third phase, foreign competition in the domestic market was expected to encourage competition with imports, and Indian products that survived this competition were expected to confront the same global products elsewhere in the world. This strategy posed an immediate challenge to each of the three stages built into India's technology policies.

The divergence between the needs of a liberalizing Indian economy and the technology policy strategy is quite evident if we go back to the various stages noted in Figure 1. To begin with, academic freedom envisaged in the technology policies, at its best, encouraged scientists to seek global recognition. The less ambitious among them would seek to answer variations of questions raised in the developed world, while the more ambitious would seek to raise new questions that would gain attention in the global academic community. Neither of these sets of achievements was necessarily relevant to the demands of a liberalizing economy. The products such an economy demanded often had little to do with cutting-edge science. Wrist watches, that were previously functional, grew by transforming themselves into items of fashion jewellery ${ }^{16}$. The market could perceive even old goods as new products. Ancient Vedic hymns have been known to be treated as new products when presented through videos. The products the market demanded could thus be very different from what the scientists liked to help create. While academic and economic freedom may have helped attract more scientists, it did little to get them to target the goals the market was setting.

The link between S\&T was also affected by the process of liberalization, which generated an ethos that encouraged a withdrawal of the Government. While it was expected that the private sector would step in, there was often little reason for the latter to do so on a very large scale. Since the products scientists were interested in were not always the ones that the market sought, the private sector had no direct incentive to contribute to the general training process. The dissemination of products evolved in the S\&T establishment too tended to be limited. Without a direct connection with the market the focus of the establishment tended to be on the functionality of a product, while the market often sought products 
based on a variety of considerations, including nonfunctional elements such as fashion. It is thus difficult to see the underlying logic of current Indian S\&T policies meeting the requirements of a market-driven economy.

\section{Towards an alternative Science and Technology Policy}

Even as Solow's thesis that technological progress has contributed more substantially to long-term growth than capital accumulation has gained quiet acceptance, its impact on mainstream economics has been somewhat less than could have been expected. The efforts of mainstream economics to capture the role of technology have concentrated on microeconomics rather than macroeconomics ${ }^{17}$. The effort to capture the role of technology in national growth would be more rewarding if we do not confine ourselves to the realm of neo-classical economic models. And when looking outside the mainstream neo-classical, paradigm there is much to be gained by going back to the theorising of Joseph Schumpeter ${ }^{18}$. For decades Schumpeter's ideas have tended to get less attention than they deserve, largely because of his scepticism about the neoclassical prominence for perfect competition. Schumpeter was not just critical of this emphasis on perfect competition, but even found some merit in short-term monopolies. Rather than focusing on competition within markets, he saw the impulse for growth coming from competition for new markets. Once an innovator was able to create a new market, she would have a monopoly over it for a while. The process of building on the advantage that the innovation provided would generate spillovers. As others tapped these spillovers to enter the same markets, the degree of competition would increase until such time that the original innovator lost her advantage. The process has not always worked as efficiently as Schumpeter would have liked, with monopolies often remaining for long periods of time. But it did capture the interaction between technology and economic growth through two stages: the innovation stage, and the spillover-cum-catching-up stage.

A comprehensive evaluation of the Schumpeterian model is well beyond the scope of this article, but even a cursory glance at the Indian post-liberalization experience suggests that the basic premise of the economy creating new products, often as new monopolies, is not without its merits. A large number of new products have entered the Indian market. Much of the attention on these products has been focused on the access provided to the Indian customer to global brands, often creating near-monopoly conditions. Sometimes the high-end new markets created by the global markets have left room for local products to grow, typically with greater spillover effects. To cite a popular example, in parts of India the entry of relatively high priced global brands of potato chips vacated space for freshly made potato chips to occupy the lower end of this market. Even in this simple example the social and economic dimensions of the choice of products, and hence technology, cannot be missed. A fundamental departure of the Schumpeterian logic from that embodied in Indian S\&T policies is the primacy given to technology over science. The economy grows in spurts led by innovations. The success of these innovations is determined by the market and not by the scientific community. Some of these innovations can spur new scientific discoveries or tap into existing knowledge. But it is also possible that the innovations are in practices that are not traditionally considered to be a part of S\&T, including changes in marketing. In order to capture this process in its entirety, it is necessary to use a definition that not only provides the pride of place to technology but is also broad enough to capture all aspects of this process. The definition that is, arguably, best suited to do so is Bernal's ${ }^{19}$ view that 'A technique is an individually acquired and socially secured way of doing something; a science is a way of understanding how to do it in order to do it better'. Even without necessarily committing ourselves to the rest of Bernal's views, we can build on the fact that this definition emphasizes three elements of technology that are consistent with the Schumpeterian approach. First, there is an acknowledgement of the relationship between the technique and the individual, allowing for a collection of techniques - which we can refer to as technology - to be acquired by groups of individuals. The techniques in question can be as varied as, say, from putting on a switch in a larger technological process to making a software program individually. The process of acquiring this technique could also follow a wide range of possibilities. The technique could be a public good in the economists' sense, that one individual can acquire it without reducing its availability to another individual, and no one is excluded from acquiring it. At the other extreme it could be a private good, where those who do not pay to acquire it are excluded from using it. This prominent place for the individual is particularly useful in understanding the process of innovations. Second, the emphasis on the socially secured way of doing things focuses much needed attention on the social relations involved in the use of technology. Social anthropologists have in considerable ethnographic detail noted the social processes involved in technology in both traditional and modern societies ${ }^{20}$. Some of the interaction between tradition and modernity in the realm of technology could be benign, as in the symbol of a project being taken to a temple prior to critical stages in that project. In other cases, a conflict between traditional and modern knowledge could result in less than ideal consequences. In the Schumpeterian sense, it is only when something is socially secured that it can be used in society in a way that is economically useful; it is this acceptance by society that determines the success of an innovation. Third, the comprehensiveness of this definition merits some attention. The use of the 


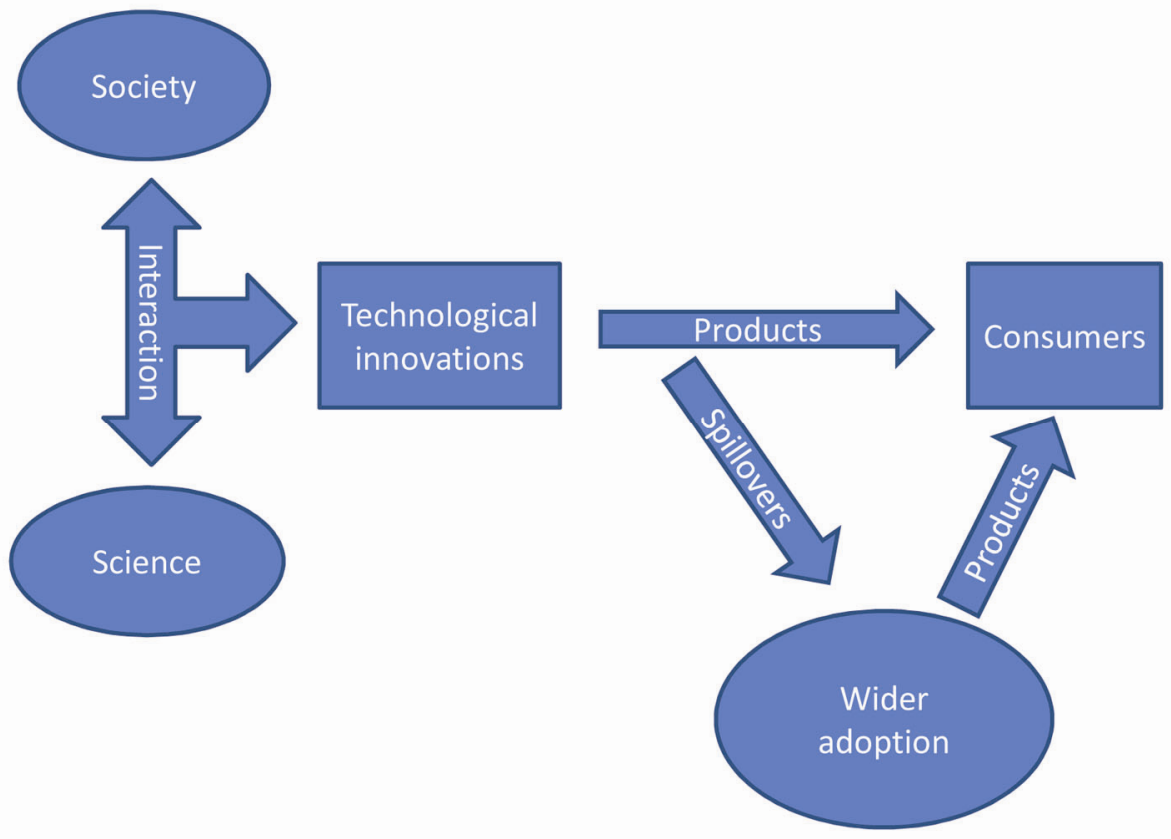

Figure 2. The role of technology in innovation-led growth.

term 'doing something' ensures there are no boundaries placed on what can be considered technological. Several elements that are not usually considered technological, such as business models, would be cases of 'doing something' and hence fall within the scope of this broader definition of technology. This militates against any tendency to restrict the consideration of technological issues to those involving considerable resources and high levels of complexity. This is particularly useful in cases where innovations that have a wide-ranging socio-economic impact are not major technological discoveries in themselves. The communications technology that made e-mail possible was undoubtedly a major breakthrough in S\&T. But the innovation of free e-mail, which is what transformed the use of this service, was based more on the economics of the service rather than any additional scientific input.

An effective S\&T policy would then intervene in these three dimensions of technology in a way that first encourages innovations, and then the spillovers that lead to a wider acceptance of this technology. Figure 2 broadly captures the logic of the role of technology in such a policy.

The centrepiece of this process is the technology that is embodied in innovations. Given the broader definition of technology that has been borrowed from Bernal, it would be virtually impossible for innovations to occur without technological change. For these technological innovations to be successful, they would need social acceptance. The innovations would thus ideally arise from the interaction between science and society. The innovator could directly, or in alliance with others, take the product to the consumers. This process however would have spillovers at various stages, from the generation of the idea to the marketing of the product. This would result in a wider adoption of the technology, leading to additional products to the consumers. An effective S\&T policy would encourage interventions in the S\&T elements at various stages of this process.

This will require at least three departures from previous policies. First, it would encourage interaction between science and society. In the earlier policies, the role of society was largely confined to developing a scientific temper. In the new policy, the interaction would have to be at different levels. Individuals would need to move between being scientists and playing other roles in society, including being entrepreneurs. It should be possible to create institutions that are the result of collaboration between, say, scientists and the corporate sector. Such interaction would enable scientists to look beyond the appreciation of the scientific community, thereby opening them to the possibility of a much wider range of socially acceptable innovations. This process cannot also deal solely with the market as it emerges. The State would have to look at ways to develop the market for socially necessary products, including something as basic as food. Such an interrelationship between a competitive market and social needs has been advocated in other countries, as can be seen in the Daejeon Declaration on Science, Technology, and Innovation Policies for the Global and Digital Age adopted by OECD ministers on 21 October 2015.

Second, the policy would encourage the transformation of an innovation into regularly made products and services. This could involve interventions in a variety of 
areas. There would be a need to link the innovator to effective sources of financing. This would in turn require going beyond state financing to enabling a dynamic financial system. The policy would also have to remove various other bottlenecks in the road from innovation to products. And it would be necessary to guard against the use of scarce resources for products that are not socially essential and may not have a market.

Third, the policy would have to create a climate that encourages the spillover effects of an innovation. This would have to be done in way that helps generate rapid growth from an innovation, but at the same time does not create a climate that discourages innovation. It would thus be necessary to first have an effective intellectual property rights system in place to protect the interests of the innovator. The effectiveness of this protection would determine whether industry feels the need to invest in R\&D. At the same time an effective climate must be created, including providing adequate infrastructure, for the non-protected aspects of the innovation to spread. For instance, there may be elements of an innovation that are not novel enough to gain protection as intellectual property, but are still not widely used. The spillover from a successful innovation could help the spread of such practices, and the new policy should encourage it.

While the specifics of a new Science and Technology Policy are open to debate, as it indeed should be, it is quite evident that the underlying logic of earlier S\&T policies is becoming increasingly inconsistent with the demands of the emerging Indian economy and society.

1. Solow, R. M., Technical change and the aggregate production function. Rev. Econ. Stat., 1957, 39(3), 312-320.

2. Garg, R. and Dua, P., Foreign portfolio investment flows to India: determinants and analysis. World Dev., 2014, 59, 16-28.

3. Didiera, T. and Schmuklerb, S. L., The financing and growth of firms in China and India: evidence from capital markets. J. Int. Money Finance, 2013, 39, 111-137.

4. Siemiatycki, M., Message in a metro: building urban rail infrastructure and image in Delhi, India. Int. J. Urban Reg. Res., 2006, 30(2), 277-292.
5. India, G. O. (15 March 1964). Government of India's Scientific Policy Resolution, New Delhi, 1958; unesdoc.unesco.org/ images/0015/001543/154344eb.pdf (retrieved on 19 November 2015).

6. India, Government of India's Scientific Policy Resolution, New Delhi 1958, 1964, p. 2.

7. Krishnaraja Wadiyar, IV, The underdog as scientist. In Bengaluru, Bangalore, Bengaluru: Imaginations and their Times (ed. Narendar Pani, S. R.), Sage Publications, New Delhi, 2009, pp. 104106.

8. Udgaonkar, B., Implementation of the Scientific Policy Resolution. Econ. Polit. Wkly, 1970, 5(52), 2091-2095.

9. Cited in Singh, B. P., Science communication in India: policy framework. J. Sci. Temper, 2014, 2(1\&2), 141-151; 144.

10. India, G. o., Science and technology policy 2003; www.csir. res.in: www.csir.res.in/external/heads/aboutcsir/Policy2003.htm (retrieved 18 November 2015).

11. India, G. o., Science and Technology Policy 2003.

12. India, G. o., Science, Technology and Innovation Policy, Department of Science and Technology, New Delhi, 2013, p. 2.

13. India, Science, Technology and Innovation Policy, 2013, p. 2.

14. Dasgupta, B., India's green revolution. Econ. Polit. Wkly, 1977, 6/8(12), 241-260.

15. Narasimha, R., Science, technology and the economy: an Indian perspective. Technol. Soc., 2008, 30, 330-338; 331.

16. Bhat, B. and Bowonder, B., Innovation as an enhancer of brand personality: globalization experience of Titan industries. Creat. Innov. Manage., 2001, 10(1), 26-39.

17. Stiglitz, J. E. and Greenwald, B. C., Creating a Learning Society: A New Approach to Growth, Development, and Social Progress, Columbia University Press, New York, 2014.

18. Schumpeter, J. A., Capitalism, Socialism and Democracy, Harper, New York, 1943.

19. Bernal, J., Science in History, Vol. 1, Penguin, Harmondsworth, 1969 , p. 47.

20. Hess, D., Technology and the development of science and technology studies. In Handbook of Ethnography (eds Atkinson, P. et al.), Sage, London, 2001, pp. 234-245.

ACKNOWLEDGEMENT. I thank Prof. V. S. Ramamurthy (NIAS, Bengaluru) for his valuable comments.

Received 20 November 2015; revised accepted 18 January 2016

doi: $10.18520 / \mathrm{cs} / \mathrm{v} 110 / \mathrm{i} / 1624-1629$ 